Corresponding Author:

Chia Kuang Lee

chia@ump.edu.my

Received: 5 August 2019

Accepted: 14 August 2019

Published: 18 August 2019

Publishing services provided by Knowledge

(c) Chia Kuang Lee et al. This article is distributed under the terms of the Creative Commons

Attribution License, which

permits unrestricted use and

redistribution provided that the

original author and source are credited

Selection and Peer-review unde the responsibility of the FGIC2019 Conference Committee.

\section{Status and Barriers Impeding Utilization of Project Management Tools: Epidemic for Tripartite Construction Parties in Malaysia}

\section{Chia Kuang Lee ${ }^{1}$, Tak Wing Yiu ${ }^{2}$, Wei Xin Lim³ ${ }^{3}$ Adekunle Qudus Adeleke ${ }^{1}$, and Tien Choon Toh ${ }^{4}$}

${ }^{1}$ Senior Lecturer, Faculty of Industrial Management, Universiti Malaysia Pahang, Lebuhraya Tun Razak, 26300 Gambang, Kuantan, Pahang

${ }^{2}$ Senior Lecturer, Faculty of Engineering, Department of Civil and Environmental Engineering, The University of Auckland, Private Bag 92019, Auckland 1142, New Zealand

${ }^{3}$ Graduated Student, Project Management Programme, Universiti Malaysia Pahang, Lebuhraya Tun Razak, 26300 Gambang, Kuantan, Malaysia

${ }^{4}$ Assistant Professor, Department of Surveying, Lee Kong Chian Faculty of Engineering and Science, Sungai Long Campus, Jalan Sungai Long, Bandar Sungai Long Cheras 43000, Kajang, Selangor

\section{Abstract}

Project management tools have been widely used in construction project life cycles to monitor progress, evaluate payments/claims, and manage construction works worldwide. Despite their capability in helping project managers to achieve specific objectives within time, budget, and standards, not every construction organization in Malaysia would fully utilize these tools due to several challenges. As numerous studies substantiate the importance and of project management tools, lackluster adoption rates have led to productivity problems, project delays, and maturity problems at both project and enterprise levels in the construction industry. This study investigates the level of implementation and addresses the significant barriers that impede the utilization of project management tools. A survey was administered to well-known construction companies in Malaysia. This study revealed that the implementation level was discouragingly low, and the top 5 barriers were: (1) financial considerations, (2) restrictions on human capital, (3) high annual turnover, (4) lack of technology awareness, and (5) organizational culture. These findings suggest that the Malaysian construction industry should: overhaul financial and human resource limitations, increase assistance for users, and boost the partial implementation of basic techniques of project management to the maximum extent possible. The practitioners can understand the dynamics and causes of predicaments to the full implementation of project management tools in their respective companies. As for academicians, these findings help theoretical development and literature arguments on our current construction industry as a whole and optimistically help finds ways to make the Malaysian construction industry more efficient.

Keywords: barriers, project management tools, Malaysian construction industry 


\section{Introduction}

A Project is a temporary endeavour that has a beginning and end date. Project management, on the other hand, is "the application of knowledge, skills, tools, and techniques to project activities to meet project requirements" (PMI, 2013). Project-based organizations, often defined as "various organizational forms that create a temporary system for carrying out their work" (PMI, 2013), require management tools to initiate, plan, execute, monitor and control activities. Notably, the tools are numerous and continue to grow (Jonsdottir, Ingason, \& Jonasson, 2014). Project Management Tools have a significant effect on project productivity on an enterprise level, directly as well as indirectly, depending on the sectors analysed (Devaraj \& Kohli, 2003; Gilchrist, Gurbaxani, \& Town, 2001; Gordon, 2000; Gretton, Gali, \& Parham, 2004). Worth note-taking, adequacy of methods and tools are nevertheless the antecedents of project maturity (Spalek, 2014). The assessment of project management maturity has been done in the form of assessing project management practice (Sanjuan \& Froese, 2013). Both maturity and productivity have been el9inked to the use of project management tools.

Several studies have substantiated the virtues of PM Tools. A study by Ika, Diallo, and Thuillier (2010) which involved empirical survey to 600 project coordinators in Africa demonstrated a strong correlation between the use of project monitoring \& evaluation tools and project management success. Another empirical study which involved 154 project professionals working in the UAE by Mir and Pinnington (2014), showed investment in project management practices increases project management performance and enhances overall project success by several measures, including project efficiency, positive impact on the team and customer, business success and future preparation. Asserted by Mutesi and Kyakula (2011), the benefits derived from the use of technology tools are reduced mistakes in documents, easiness of complex tasks, time-saving, and increased productivity. On the whole, the investments in management technologies and tools contribute to the growth of productivity on an enterprise level, through the direct effects derived from the intensification of the capital, as well as to the overall effect on the factor contributing to productivity (Ollo-Lopez \& Aramendia-Muneta, 2011).

Despite the advancement and availability of project management tools available to the industry, project success was not significantly improved (Mir \& Pinnington, 2014). This notion asserts that tools are without its use if underutilized in organizations. The types and level of usage of the available project management practices and tools are 
often overlooked and unheeded among the overgrowing interests of academics and practitioners (lka et al., 2010).

Weak project management practices seem to be a plague within project owner organizations (Sanjuan \& Froese, 2013). Despite the benefits of project management tools, White and Fortune (2002) showed that only a small number of tools and techniques of project management were deployed in project-based organizations. They observed among the limitations and drawbacks impart on the tools include inadequate for complex projects, difficult to model real-world, time-consuming, fail to predict future, constrained in views, not cost-effective, lack of training, unsuitability, immature, too much emphasis on standard, no lessons learned. In another research by Murphy and Ledwith (2007) in Irish high technology Small Medium Enterprise (SME) companies also suggested that project management tools have been used to a limited extent. In Malaysia, particularly, investigation done by Ibrahim, Roy, Ahmed, and Imtiaz (2010) have depicted that low productivity in the industry has significantly been associated with low usage of technology.

\section{Epidemic of Underutilized Pm Tools}

Information \& Communication Technologies (ICT) has benefited the construction industry. In Malaysia, Abdul Kareem and Abu Bakar (2011) reported that among the major benefits of ICT to the Construction Industry were client satisfaction, cost reduction, management improvement, competitiveness advantages, improvement in business success criteria (i.e. efficiency, effectiveness and performance), information quality, organizational growth, work relations, and also increment in response rate, work flexibility, market share, reduction of working time.

The inclination and development of ICT have consequently developed various compute based tools to aid construction projects. Lately, Building Information Modelling (BIM), has been gaining widespread attention and interest in the construction industry. Academic wise, BIM allow students to experience practice project management in real projects (Peterson, Hartmann, Fruchter, \& Fischer, 2011). However, the debut of BIM depends on the intended level of usage of information and communication technology (ICT) (Lee, Yu, \& Jeong, 2013).

Given the fact that most project management tools are in the form of ICT, this assertion greatly implies that the utilization of project management tools reflects both the maturity and the readiness of BIM acceptance in the industry. The advancement and progression of tools need to be aligned with the management processes to maximize its potential 
(Froese, 2010). Arguably, construction management tools are challenging to learn in the first place. Organization and technology need to work together. The involvement of project managers must be robust to ensure the coherence of tools and technologies utilizations in the organization (Hartmann, van Meerveld, Vossebeld, \& Adriaanse, 2012). Effectiveness in project management can be increased, provided awareness coupled with training in a tool is adequate and lackluster of tools to manage projects is overcome (Papadaki et al., 2014; Pereira, Tenera, \& Wemans, 2013).

According to Sanjuan and Froese (2013), lackluster of awareness and low confidence level of the value of project management are the pitfalls of project management practices and delivery in organizations. This explains the shortcomings of tools utilization in construction companies. It is a fact that not every construction companies will fully utilize project management tools. According to Ahuja, Yang, and Shankar (2009), construction organizations are slow in adopting technology tools. Without full utilization of Project Management Tools, these benefits may not be sustained in the long run. Research by Aouad, Kagioglou, Hinks, and Sexton (1999) suggested that technology tools are blockers rather than enablers of process improvement. There are assertions that the utilization of project management tools has both positive and negative effects. The first asserts that the higher adoption and use of the technology tools, the higher the productivity of the companies; while the latter implies that technological tools could have a negative impact due to the fact of great investment effort in the tools, and the high rate of capital depreciation of already installed or implemented tools is not compensated by earnings in productivity (Gilchrist et al., 2001; Greenan, Mairesse, \& Topio-Bensaid, 2001; Gretton et al., 2004; Lehr \& Lichtenberg, 1999).

Despite the contrary allegations of project management tools, the industry still heavily relies on these means of tools in managing multi-billion and mega projects. It is imperative that project managers understand the barriers that impede the full utilization of such tools in the organization. There is a need to address this issue, and the industry should leap forward to fix the quandaries underpinning utilization of project management tools. Once these factors of barriers are apparent, the project managers can eventually (1) overhaul the problems in tools adaptation in companies, (2) fostering acceptance of project management tools, (3) enhance project delivery process, (4) upgrade and enhance the existing project management tools as effective means in managing contractual claims and governance 


\section{Development of Project Management Tools (the Year 1950-1990's)}

Modern project management has its roots back in the late 1950s with the development of Critical Path Method (CPM), and Program Evaluation Review Technique (PERT) (Hebert \& Deckro, 2011). Since the 1950s, network-based techniques are commonly applied in project management (Shtub, 1997). With the merits of CPM, PERT, and PDM, two different professional project management institutes were formed. International Project Management Association or known as IPMA was formed in North Europe back in 1965, followed by the Project Management Institute (PMI) establishment in the USA and Canada in 1969 (Stretton, 2007). Following that, project management tools continue to propagate (Hebert \& Deckro, 2011).

\section{Development of Project Management Tools (the Year 2000's)}

The Project Management Institute (PMI) particularly has continued to grow significantly. This institute advocates, develop and supports the use of project management tools to project success (Ika et al., 2010). Empirical research in 236 companies by White and Fortune (2002) showed that popular project management tools used included Critical Path Method (CPM), Work Breakdown Structure (WBS), Gantt Charts, Graphical Evaluation and Review Technique (GERT), Programme evaluation and review technique (PERT), and Project Management Software. The top 3 tools used were Project Management software, Gantt Charts, and Work Breakdown Structure. Another research by Besner and Hobbs (2004) also demonstrated that 753 project management practitioners extensively utilize PM software, Gantt chart, and work breakdown structure.

Research by Murphy and Ledwith (2007) showed that 40 respondents from small and medium project enterprise reported that Microsoft Project, Gantt chart and Critical Path Method are envisaged as the top 3 tools used in managing projects. Recent surveys among 50 project management practitioners covering construction industry by Jugdev, Perkins, Fortune, White, and Walker (2013) also confirms that project management tools include Gantt Charts, Work Breakdown Structures, Critical Path Method, Program Evaluation and Review Technique (PERT), strengths weakness, opportunities and threats (SWOT). The software used specifically includes Microsoft Project, Primavera, and Excel. Microsoft Project software invariably has been a hot debut since the 1990's. This software has consolidated all the essence of Activity on Node (AON) format, compliments 
the precedence diagramming method and display the progress and relationships of activities in Gantt Chart View (Hebert \& Deckro, 2011). Microsoft project software took its earliest form in 1992 and had several versions until 2010. Besides Microsoft Project Software, Primavera Software has incorporated the elements of project scheduling and networking and took various versions since the 1990's. It has been considered as one of state of the art tools in contemporary project management. Primavera software is similar to Microsoft Project; however, it is more advanced and more superior in terms of complexity and functionality. It enables multiuser access and incorporates various multiple projects at once (Salas-Morera, Arauzo-Azofra, García-Hernández, PalomoRomero, \& Hervás-Martínez, 2013).

\section{Potential Barriers Underpinning Utilizations}

The term "barriers" refer to the several certain factors that affect or hinder adoption and implementation of project management tools in construction companies. Overall, the barrier discussed in this paper is organized as follows, namely: financial considerations, organizational culture, attitude, lack of technological awareness, infrastructure, annual turnover, and restriction of human capital.

\subsection{Financial constraints}

Financial considerations pose a major constraint on the technology tools investments decision (Peansupap \& Walker, 2005). Investments cost and unfavorable financial condition such as the high price of technology, the requirement on large investment, liquidity constraints, and so on are the potential barriers to technology tools investment ( $\mathrm{Hol}-$ lenstein, 2004). Besides, hiring qualified personnel would also be costly (Ssewanyana \& Busler, 2007). Asserted by Mutesi and Kyakula (2011), technology tool is constrained by the high cost of investment and recruitment of professionals. Construction firms are not providing enough caveats in investing in ICT systems development and skilled personnel (Alaghbandrad, Nobakht, Hosseinalipour, \& Asnaashari, 2011).

\subsection{Organizational culture}

Organizational culture can be described as a set of norms, beliefs, principles, and ways of behaving that together give each organization a particular character (Brown, 2002). A firm's decisions are limited by its structural characteristics, which affect its ability 
to adopt innovations in accordance with the benefits and costs involved (Moriones \& Lopez, 2007). Once a company decides to implement new project management tools, there might occur some cultural changes in the organization. Cultural changes of the organization itself are more difficult and time consuming compared to technical changes because culture affecting every facet of the organization, including management styles, attitudes, standards, adaptability to change and power equilibrium (Milis \& Mercken, 2002; Turner, 2008).

At the organizational level, the technology tools implementation constraints include basic levels of computer experience, time available to learn, and the identification of clear benefits of technology tools used. It also includes time available to share information, quality of personal contact, and geographical distance. Notably, it is not easy to accustom those practitioners with the technology tools, convince them to trust and use the new tools, as some of them may have been adapted with paper-based systems in their work over the years. It is believed that the best way to accustom construction practitioners with technology tools is to let them experience the benefits themselves (Alaghbandrad et al., 2011).

In reality, firms have different ways of organizing their activities and resources, and their decisions for technology tools adoption vary accordingly. Organizational factor influences not only the firm's innovative capability but also in the tool's contribution to the organizational principles followed by the firm (Moriones \& Lopez, 2007).

\subsection{Attitude}

Behaviour is the action or reaction of a person in response to external or internal stimulation. It is believed that personal attitudes always contribute to shaping and affecting behaviour at work. New project management tools, change of technology, or culture may cause confusion, panic, and resistance among every individual in the organization (Milis \& Mercken, 2002). Due to the expected resistance, management chooses to keep the users out of the project for as long as possible, which would probably result in mistakes or miscomprehension among the users (Milis \& Mercken, 2002). Thus, this has become a barrier that impedes the full utilization of technology tools among companies.

In predicting technology use, the salient constructs underlining attitudes include perceived ease of use, perceived usefulness, and complexity (Taylor \& Todd, 1995). Perceived ease of use refers to the degree of difficulty in understanding and operating (Rogers, 2003). Perceived usefulness, on the other hand, refers to the capability of 
the system/ tool would enhance job performance. Later in 2008 , another noticeable construct of attitudinal beliefs includes "computer anxiety," which refers to an individual apprehension in using computers (Ventakesh \& Bala, 2008).

The introduction of innovations can be intimidating for employees, mainly if it requires them to change their current practices or acquire new skills (Beatty, Shim, \& Jones, 2001). There are varieties of people who have been using their methods successfully for many years, and this might encounter resistance to change when introducing the new project management tools. This is due to the lack of understanding in the new tools function, the benefits of using the tools and even believes that the tools will create more work. Besides, Alaghbandrad et al. (2011) stated that there are managers indicated that they had experienced resistance from 'older' workers whenever modern technology has been implemented. User resistance also occurs lackluster when inexperience senior managers introduce the applications to the organization (Peansupap \& Walker, 2005).

Since the improvement or enhancement of technology tools often lead to changes in the physical or technological environment, people should get acquainted with their changing working environment. They have to learn to work with new or changing technologies in an altered environment (Turner, 2008). As if this happens in a project team, the team members should be cohesive, well-motivated, and committed to the project, as a way trying to adapt to the introduced project management tools

\subsection{Restrictions of human capital}

The human capital restriction is another barrier that impedes full utilization of project management tools in construction companies. Adoption of these technology tools may be fraught by human capital restrictions, for example, a general shortage of highly skilled workers, lack of tools specialists, insufficient training, and so on (Hollenstein, 2004). An inadequate number of trained workers implies fewer innovations. Shortages of staff cause insufficient time for the use of software project management tools forces companies to limit the utilization of management tools in practice (Sukhoo, Barnard, Eloff, \& Van der Poll, 2004).

Apart from that, individual characteristics do play a crucial role in the implementation of new technologies and management tools in an organization (Mahmood, Hall, \& Swanberg, 2001; Venkatesh \& Morris, 2000). Notably, qualified and highly educated workers would increase organizational readiness for innovation (Moriones \& Lopez, 2007). Plants with advanced technologies eventually would require high-skilled workers (Doms, Dunne, \& Troske, 1997). High-skilled workers enhance the tools and thus making 
the investments in project management tools worthy and more accessible (Morgan, Colebourne, \& Thomas, 2006).

Another daunting factor in human capital is to explain worker disagreement over the introduction of new work practices between younger workforce and senior age personnel. In organizations with a younger workforce, managers seem to have more enthusiastic towards technology tools adoption. The opposite occurs with older and more experienced workers, where they will be more reluctant to accept innovation because they would consider themselves experienced and established (Moriones \& Lopez, 2007).

\subsection{Lack of technological awareness}

Lack of technology awareness is depicted to have impeded full utilization of project management tools (Pamulu \& Bhuta, 2004). New technologies enable construction organizations to process and store their information easily, and huge amount of data can be transferred quickly (Alaghbandrad et al., 2011); however, current workloads deviate their focus on emerging new tools. Thus, awareness deficiency might lead to productivity problems and deter technology tools investments decision and obscure the technology tools investment opportunity (Peansupap \& Walker, 2005). Limited awareness and understanding of potential gains by using these project management tools can be a significant loss (Adriaanse, Voordijk, \& Dewul, 2010).

\subsection{Infrastructure deficiency}

Infrastructure deficiency is one of the barriers that hinder technology tools implementation (Gichoya, 2012). Infrastructure is an underlying base or foundation for an organization or system. Malaysia is currently facing infrastructure deficiency, where the full potential of the internet has not been utilized by Malaysian construction companies (Abdul Kareem \& Abu Bakar, 2011). Technology tools infrastructure at project sites is one of the important factors and need improvement in the construction industry (Ahuja et al., 2009). Among the drawbacks in implementing and managing technology management tools were identified as, inefficient use of software, ill-defined processes, and infrastructure-related problems (Isikdag, J.Underwood, Kuruoglu, Goulding, \& Acikalin, 2009). Without a widespread and high-quality infrastructure, it is not possible to exploit technological power completely (Alaghbandrad et al., 2011). 


\subsection{Insufficient annual turnover}

It is depicted that insufficient annual turnover of a company might become a barrier that impedes the utilization of project management tools. Previous studies by Ahuja et al. (2009) showed that SMEs with higher turnover have higher adoption of ICT. These organizations can handle the initial cost, cost of updating and maintenance cost of the technology tools, mainly for effective adoption of the tools for building project management. The basic stumbling block of full implementation of project management tools is the lack of genuine value (ROI). Arguably annual turnover of a company does have impacts on the implementation of technology tools.

\section{Research Objectives}

This paper presents two objectives. The first objective is to investigate the status quo of project management tools implemented in construction companies, and the second objective is to solicit the respondents' perception on the barriers that impede full utilization of the tools in their respective companies. To propagate the importance of project management tools convincing and compelling to the practitioners, it will be interesting to know the implementation level and the barriers to allow the practitioners to elevate the predicaments and improve the status quo.

\section{Methodology}

A questionnaire was developed and administered to 135 different well known major construction companies in Malaysia. These targeted companies handled more than 20 million ringgit Malaysia (USD 6 Million) worth of projects in Malaysia. The questionnaire consists of three parts. The first part intends to obtain the demography of respondents; the second part focused on the implementation level; while the third part investigates the barriers that impede the utilization of project management tools in their respective companies. To solicit the users' perception on the implementation level, two scales namely "Implemented/Utilized", and "Not implemented/Not utilized" were probed. To obtain the degree of the barriers, a five-point scale range from 1 (not important) to 5 (extremely important) was adopted to determine the relative degree of importance and relative Importance Index (RII) of the barriers in impeding the utilization of tools. Previous studies by Kometa, Olomolaiye, and Harris (1994) in identifying the relative importance of various causes and effects of construction delay have utilized RII. Research by 
Sambasivan and Soon (2007) also adopted RII in soliciting the relative importance of factors that causes delay and prioritizing the ranks of causes and effects of project delay. Overall, the relative importance (I) for each factor was calculated as follows:

$\mathrm{I}=\frac{\sum_{i=1}^{5} W_{i} X_{i}}{\sum_{i=1}^{5} X_{i}}$, where

$i=$ Response category index; whereby $1=$ not important, $2=$ slightly important, $3=$ moderately important $4=$ very important, $5=$ extremely important

$W_{i}=$ Weight assigned to $i$ th response $=1,2,3,4,5$ respectively.

$X_{i}=$ Frequency of the $i$ th response given as a percentage of the total responses for each cause.

The Relative Important Index (RII) had a range from 1 until 5; the higher value of index implies the higher degree of barriers. The average index for the main barrier is the average of all the indexes of their respective barrier elements. The computed index was then used to rank the different sub-barriers and the main barrier as perceived by the contractors. About 42 Companies comprising of Grade-7 Contractors, Developers and Charted Consultants responded to this survey, which achieved a response rate of $31.1 \%$. A separate Spearmen's Rank correlation was done to test the agreement between the tripartite parties. The spearman rank correlation coefficient can be tested to measure statically the degree of agreement related to the rankings of barriers perceived by contractors, developers, and chartered consultants. The higher the correlation coefficient at a significant level, 0.05 would indicate a stronger agreement between the groups of respondents (Hwang, Zhao, \& Toh, 2014; Sambasivan \& Soon, 2007).

\section{Results and Discussions}

The primary data were analyzed from the perspective of consultants, contractors, and developers. The implementation level of project management tools is analysed collectively. The status of implementation was probed based on a "yes"/"no" on "Implemented, not implemented" column, while each respondent's perceptions on barriers were computed by RII (Relative Importance Index). The demographics of respondents is portrayed in Table 1 below. Table 2 denotes the status of implementation, Table 3 depicts the ranking of barriers perceived (Overall); Table 4 shows the RII and ranking of barriers according to categories of respondents; and Table 5 describes the Spearman's Rank Correlation Coefficients of the ranking of Consultants, Developers, and Contractors.

Referring to Table 1, the characteristics of the subjects are discussed. Of the 135 different construction companies surveyed, 42 surveys were returned. All responses were complete and usable. Majority of the respondents were Company Managers 
TABLE 1: Demographic Characteristics of Respondents.

\begin{tabular}{l|c|c|}
\hline Description & Frequency & Percentage (\%) \\
\hline Positions & & \\
\hline Company Director & 11 & 26.20 \\
\hline Company Manager & 12 & 28.60 \\
\hline Project Manager & 6 & 14.30 \\
\hline Project Engineer & 9 & 21.40 \\
\hline Project Coordinator & 1 & 2.40 \\
\hline Senior Architect & 1 & 2.40 \\
\hline Senior Quantity Surveyor & 2 & 4.80 \\
\hline Type of Organizations & & 38.10 \\
\hline Developer & 16 & 42.90 \\
\hline Contractor & 18 & 19.00 \\
\hline Consultant & 8 & \\
\hline Experience in Construction Industry & & 33.33 \\
\hline 5-10 years & 14 & 28.57 \\
\hline 11-15 years & 12 & 16.67 \\
\hline 16-20 years & 7 & 21.43 \\
\hline More than 20 years & 9 & \\
\hline Types of Projects Involved & & \\
\hline All more than RM 20 Million (USD 6 & & \\
\hline Million) worth of projects. & & \\
\hline
\end{tabular}

(28.6\%), followed by Directors (26.2\%), Project Engineers (21.4\%), and Project Managers (14.3\%), Senior QS (4.8\%), and having both project coordinator and architect being the least (2.4\%). The company background consists of tripartite companies, namely the Contractor companies (42.90\%), Developers (38.1\%), and followed by Consultants (19\%). A noticeable $21.43 \%$ of the respondents have more than 20 years of experience, and all respondents have at least 5 years minimum of working experience in the construction industry.

First, the paper discusses the current status quo of the implementation level of project management tools. Next, top 5 (FIVE) highest rank sub barriers, and 1(ONE) lowestranked sub barrier are presented. Followed by that, the significant level of agreement between the contractor and consultant obtained through the analysis of Spearman Rank Correlation over the seven major barriers will be discussed. Based on the rankings, prescriptions that could overhaul these barriers are discussed.

Referring to Table 2, "Excel" is the most implemented tool used (85.7\%), followed by Microsoft Project (40.5\%), Gantt Chart (38.1\%), Critical Path Method (38.1\%), Work Break Down Structure (21.4\%), Web-Based tools (14.3\%), Other Technology Tools (14.3\%), Precedence Diagramming Method (9.5\%), Program Evaluation and Review Technique, (PERT) 
TABLE 2: Implementation of Project Management Tools.

Project Management
Tools
Microsoft Project
Primavera P6
Professional Project
Management (or other
versions of Primavera
E.g. Primavera Portfolio
Management,
Primavera P6 Analytics
etc.)
Web-based tools
Gantt Chart
Critical Path Method
(CPM)
Program Evaluation and
Review Technique
(PERT)
Graphical Evaluation
Review Technique
(GERT)
Activity-On-Arrow
(AOA)
Activity-On-Node (AON)
Work Breakdown
Structure (WBS)
Precedence
Diagramming Method
(PDM)
Microsoft Excel
Other technology tools
(e.g., UBS, Microsoft
Access)

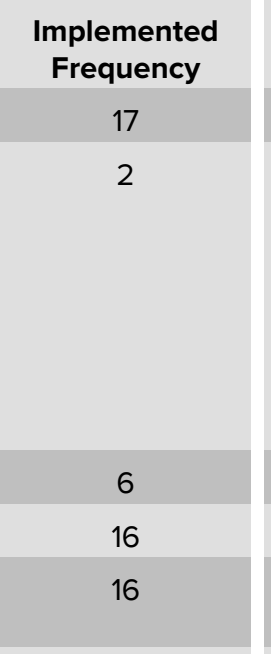

3

2

3

2

9

4

36

6

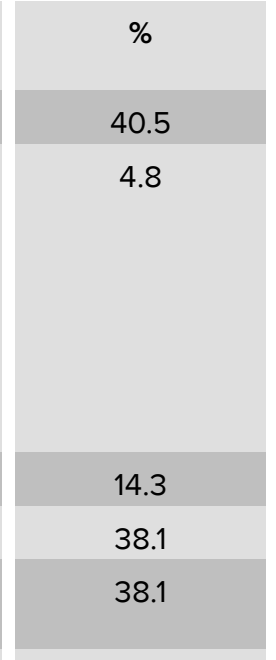

7.1

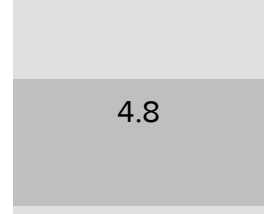

7.1

4.8

21.4

9.5

85.7

14.3

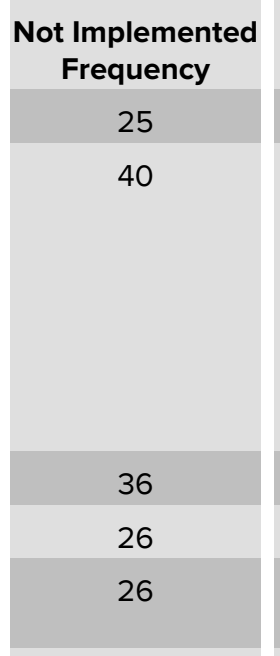

39

40

39

40

33

38

6

36
$\%$

59.5

95.2

85.7

61.9

61.9

92.8

95.2

92.9

95.2

78.6

90.5

14.3

85.7

(7.1\%), Activity-on-Arrow (AOA) (7.1\%), Graphical Evaluation Review Technique (4.8\%), Primavera P6 Packages (4.8\%), and Activity on Node (AON) (4.8\%). The figures denote that the overall implementation level of project management tools is devastatingly low.

Based on the sub-barrier elements depicted in Table 3, lack of corporate budget $(\mathrm{R} I \mathrm{l}=$ 3.641) was ranked the highest. The respondents felt that the management does not have adequate funding for management tools, and it is almost impossible to have funding reconciliation for such purpose. Given the fact that managing projects heavily rely on managing people, reliance on management tools would imply managing software and tools itself. 
TABLE 3: Relative Important Index (I) for Barriers.

\begin{tabular}{|c|}
\hline Factors \\
\hline Financial Considerations \\
\hline Lack of Corporate Budget \\
\hline Expensive Tools \\
\hline Expensive Experts \\
\hline Organizational Culture \\
\hline Cultural Changes \\
\hline Aversion of New Technology \\
\hline Acceptance of Employees \\
\hline Predicaments in Convincing Employees \\
\hline Attitude \\
\hline Computer anxiety (Confusion \& Panic) \\
\hline Perceived Lack of Usefulness \\
\hline $\begin{array}{l}\text { Perceived Lack of Ease of Use (User's } \\
\text { Lack of Confidence) }\end{array}$ \\
\hline Restriction on Human Capital \\
\hline Human Capital Problems \\
\hline Shortages of Staffs \\
\hline Unskilled personnel \\
\hline Lack of Technology Awareness \\
\hline Slow Adoption \\
\hline Senior Managers Unaware \\
\hline Bad investments in wrong tools \\
\hline Deficiency in Infrastructure \\
\hline $\begin{array}{l}\text { Quality problems of existing } \\
\text { infrastructures }\end{array}$ \\
\hline Unable to expand new infrastructure \\
\hline Unsatisfied Infrastructure \\
\hline Poor Annual Turnover \\
\hline Poor level of Turnover \\
\hline $\begin{array}{l}\text { Lack of return of investments in new } \\
\text { management tools }\end{array}$ \\
\hline $\begin{array}{l}\text { Inability of Company to Support and } \\
\text { upgrade software/hardware }\end{array}$ \\
\hline
\end{tabular}

\begin{tabular}{|c|c|}
\hline \multicolumn{2}{|c|}{ Sub-Barrier Elements } \\
\hline Index (I) & Rank \\
\hline 3.641 & 1 \\
\hline 3.512 & 3 \\
\hline 3.507 & 4 \\
\hline 3.419 & 7 \\
\hline 3.391 & 8 \\
\hline 2.815 & 17 \\
\hline 2.840 & 16 \\
\hline 3.333 & 9 \\
\hline 2.810 & 18 \\
\hline 2.745 & 21 \\
\hline 3.421 & 6 \\
\hline 3.558 & 2 \\
\hline 2.981 & 13 \\
\hline 2.917 & 14 \\
\hline 3.236 & 12 \\
\hline 3.282 & 10 \\
\hline 2.688 & 22 \\
\hline 2.757 & 20 \\
\hline 2.778 & 19 \\
\hline 2.917 & 15 \\
\hline 3.479 & 5 \\
\hline 3.257 & 11 \\
\hline
\end{tabular}

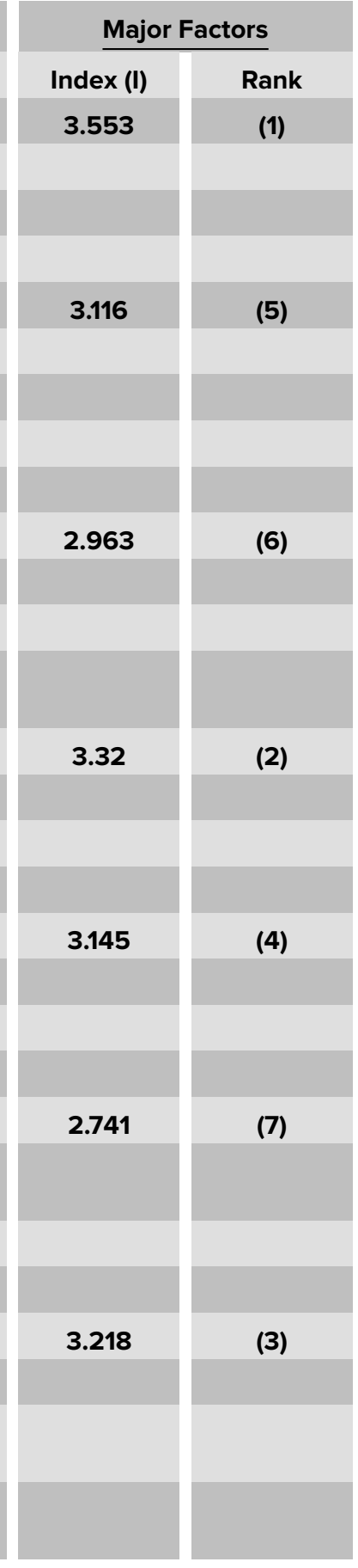

Followed by that, shortage of staffs was ranked second, with RII $=3.558$. Worth notetaking, Malaysian Construction Industry is still facing challenges in recruiting expertise that can manage sophisticated project management tools such as Primavera or Microsoft Project software effectively and efficiently. 
TABLE 4: RII and ranking of Main Barriers.

Major Barriers
Financial Considerations
Organization Culture
Attitude
Human Capital Restriction
Lack of Technology Awareness
Infrastructure
Poor Annual Turnover

\begin{tabular}{|c|c|}
\hline \multicolumn{2}{|c|}{ Developer } \\
\hline RII & Rank \\
\hline 3.211 & 4 \\
\hline 3.360 & 3 \\
\hline 3.000 & 6 \\
\hline 3.438 & 1 \\
\hline 3.375 & 2 \\
\hline 2.917 & 7 \\
\hline 3.084 & 5 \\
\hline
\end{tabular}

\begin{tabular}{|c|c|}
\hline \multicolumn{2}{|c|}{ Consultant } \\
\hline RII & Rank \\
\hline 3.500 & 1 \\
\hline 3.031 & 4 \\
\hline 3.000 & 5 \\
\hline 3.208 & 3 \\
\hline 2.875 & 6 \\
\hline 2.750 & 7 \\
\hline 3.292 & 2 \\
\hline
\end{tabular}

\begin{tabular}{|c|c|}
\hline \multicolumn{2}{|c|}{ Contractor } \\
\hline RII & Rank \\
\hline 3.889 & 1 \\
\hline 2.958 & 5 \\
\hline 2.889 & 6 \\
\hline 3.315 & 2 \\
\hline 3.185 & 4 \\
\hline 2.555 & 7 \\
\hline 3.278 & 3 \\
\hline
\end{tabular}

TABLE 5: Spearman's Rank Correlation Coefficients.

\begin{tabular}{l|l|c|c|c|}
\hline Ranking & & Consultant & Developer & Contractor \\
\hline Consultant & Correlation Coefficient & 1.000 & 0.286 & $0.857^{* *}$ \\
& Significance & - & 0.535 & 0.014 \\
\hline & N (Number of Barriers) & 22 & 232 & 22 \\
\hline \multirow{2}{*}{ Developer } & Correlation Coefficient & 0.286 & 1.000 & 0.607 \\
& Significance & 0.535 & - & 0.148 \\
\hline \multirow{2}{*}{ Contractor } & N (Number of Barriers) & 22 & 22 & 22 \\
& Correlation Coefficient & $0.857^{* *}$ & 0.607 & 1.000 \\
\hline & Significance & 0.014 & 0.148 & - \\
\hline & N (Number of Barriers) & 22 & 22 & 22 \\
\hline \multirow{2}{*}{ **Correlation } & is significant at the 0.05 level of significance. & & \\
\end{tabular}

The third highest barrier was an expensive tool, with RII=3.512. Understandable, project management tools such as Primavera, Oracle Software could be severely expensive. However, Microsoft based interfaces applications such as Excel, or Microsoft Project comes in handy and could be further implored.

Next, expensive experts were ranked the fourth highest rank, with RII reaching=3.507. Nevertheless, the respondents felt that real experts in management software and tools are not easily up for grabs. As much as the software itself, full-time experts are expensive to hire and recruit.

Ranked as fifth, the factor lack of return of investments in new management tools reached Rll of 3.479. Lack of $\mathrm{ROI}$ in these tools would hinder the management to further uptake new tools. Although not further discussed, this paper speculates that investments made on the purchased tool/model did not seem to have to yield profitable returns. Moreover, the fundamental fault is on the workforce itself, as heartfelt by the respondents mentioned above -lack of experts to fully utilize these tools.

While all the major five sub barriers have been depicted above, the least ranked barrier would be quality problems of existing infrastructures. Ranked as 22 with RII = 
2.688 , it does not seem to be major presuppositions of barrier that need to be taken care.

Overall, depicted in Table 5, the Spearman rank correlation test was used to examine the agreement level between consultants, developers, and contractors. The result shows that both consultants and contractors share the same perception over 22 barriers, with a correlation coefficient of 0.857 at a significant level of 0.05 . By only looking at the main barriers themselves, both consultant and contractor categories agreed that financial consideration poses major concern; while infrastructure poses the least concern (Table 4. On the other hand, for developers, the human capital restriction is their primary concern, with infrastructure being their least concern.

Based on the summary ranking in Table 3, the important barriers as perceived by the overall respondents were: (1) financial constraints [RII =3.553], (2) restrictions on human Capital [RII = 3.320], (3) poor annual turnover [RII =3.218], (4) lack of technology awareness [RII= 3.145], (5) organizational culture [RII = 3.116], (6) attitude [RII =2.963], (7) deficiency in infrastructure [ RII $=2.741]$.

\subsection{Prescriptions to overhaul barriers}

Notably, the survey involves construction companies that handle more than USD 6 Million worth of construction projects. The survey above suggests a low implementation of project management tools in these respective construction companies. Besides Excel, the survey indicates no more than $50 \%$ implementation in all subsequent project management tools. More attention should be given to financial constraints, restrictions on human capital, poor annual turnover, lack of technology awareness, and organizational culture. Both attitude and deficiency in infrastructure, however, were perceived as not crucial (RII below 3.00).

The respondents were prompted earlier on their willingness to uptake new and enhanced management tools to their existing tools. $85.7 \%$ of the respondents agreed that their company has the urgency to uptake and enhance their existing project management tools; while the remaining $14.3 \%$ are pessimistic on improving and enhancing new tools in their organizations.

Besides managing the triple constraints such as time, cost, and quality of a project, the expectations of the tripartite parties (namely the developers, consultants, and contractors) need to be managed ideally. While selecting contractors in their prequalification process, the selected contractors in the tender evaluation process must exhibit robust capabilities in technicality aspects, and thus mitigating the probability of impeding 
potential utilization of management tools on construction sites. On the other hand, developers and consultants (mostly working for the client in contemporary construction contract) should promptly assure the cash flow of the contractor by paying on time, and thus reducing any predicaments of project management tools in projects.

During the initiation phase, where expectations of all stakeholders are discussed, the project sponsor should take into account of the need and urgency of enhancing, or up taking new management tools in projects. And thus, the project team could savour the required budget for the development of project management tools. To overhaul lack of expertise in the organizations, management should emphasize on giving adequate in house training that would enhance tools usage and knowledge. Propagation of such knowledge should be then reinforced with management commitment from top-down. Attitude problems can be overcome with an increasing experience that diminishes computer anxiety, given that the users experience the enjoyment of using tools in day to day work. This heavily relies on organizational management support through helpdesk, and off the job training (Ventakesh \& Bala, 2008).

Government Malaysia plays an important role as well in helping the industry to progress. Hand-in-hand with the Construction Industry Development Board (CIDB Malaysia), awareness and proper training program can be held to promote project management practices in the industry. Incentive alignment strategy as the postimplementation stage of tools takes place is one of the key factors that enhance user acceptance in technology usage (Todd \& Benbasat, 1999). Particularly for the use of project management tools, Malaysian Construction Industry Development Board particularly can opt to cooperate with the Multimedia Development Corporation, or known as MDEC, which is an agency that oversees the implementation of multimedia and information infrastructures in Malaysia, and Project Management Institute Malaysian Chapter (PMIMY). In Malaysia, formal project management courses and the education training such as Certified in Project Management Professional $\left(\mathrm{PMP}^{\circledR}\right)$, or Certified Associate in Project Management $\left(\mathrm{CAPM}^{\circledR}\right)$ are delivered as means of formal training and pre-requisites for industrial practitioners in getting project management credentials, and the most predominant certification nevertheless is $\mathrm{PMP}^{\circledR}$. In practice, MDEC, serving as the backbone of the Malaysian multimedia corridor, has been actively providing rebates up to RM 2,500 (USD 600) for individual project management exam and course takers. Incentives such as grants, rebates can be provided via these tripartite agencies such as this can be implemented to increase awareness and knowledge of practitioners of the use of project management methodologies and PM tools in the companies. 
In the macro level, the Malaysian Construction Industry has been depicted to have faced predicaments in exercising the policies set out by the government, especially the contractors themselves in using and benefit from the state of the art technologies in managing projects (Ibrahim et al., 2010). Cautiously optimistic, this paper suggests that the Malaysian Government through CIDB should tackle the fundamental issues of formal project management education among practitioners. Application of new technologies requires fundamental project management knowledge, which can be strictly emphasized in the next Malaysian Construction Industry Master (CIMP 2016-2025). By advocating and propagating the need of formal project management practices aligned with its previous strategic thrust, further recommendations can be reinforced in fourth Strategic Thrust - "Develop Human Resource Capabilities and Capacities in the Construction Industry"; and sixth strategic Thrusts - "Leverage on information and communication technology in the construction industry". Development of human resource requires fundamental realignment of skill in project management knowledge and the development of tools and technologies that the industries have to offer.

\section{Conclusion}

Project management tools have been a cornerstone in the operations of construction activities. Numerous studies have proved the use of PM tools in planning, monitoring, and controlling construction projects effectively. Besides increasing construction productivity, PM Tools are capable of circumventing delays, enhancing the delivery value of projects, and increases project management maturity in organizations. Using a survey design and Relative Importance Index (RII) methodology, this study investigated the implementation level of project management tools and the barriers that impede project management tools adoption in construction companies. The first findings suggest a low implementation level of project management tools. Although Microsoft Excel was ranked the highest being adopted, the other core PM tools such as WBS and Microsoft Project are devastatingly low. The second findings assert financial considerations and lack of human resource in exercising these tools to be two highest barriers that impede PM Tool's adoption and substantiating the other main factors such as reduced annual turnover, lack of technology awareness, organizational culture, attitude, and infrastructure barriers equally being the stumbling block of adoption. The third finding concludes a consistent agreement on the barriers among), private contractors, and private consultants. To overcome these barriers, incentives alignment can be instigated by the Government sectors such as CIDB, MDEC, and non-profit organizations such as 
the Project Management Institute for the propagation of project management training. Having the tools is never adequate without knowledge advancement. Through formal training, it reinforces a positive attitude and increases adoption.

Cautiously optimistic, this paper reveals the current status quo of project management practices and standard PM tools adoption in Malaysia, so that the key players can give proper attention on the important factors and make dynamic efforts to reduce barriers of project management tools utilization in projects. The practitioners can understand the dynamics and causes of predicaments to the full implementation of project management tools in their respective companies. As for academicians, it helps theoretical development and literature arguments on our current construction industry as a whole and optimistically finds ways to take the Malaysian Construction Industry for better improvements.

\section{Acknowledgement}

We would like to thank Faculty of Industrial Management and FIM's Governance and Integrity Centre, Universiti Malaysia Pahang for the financial support by sponsoring this paper to be presented in the FGIC 2nd Conference on Governance and Integrity 2019.

\section{References}

[1] Abdul Kareem, H. I., \& Abu Bakar, A. H. (2011). Identifying IT Benefits for Malaysian construction companies. Journal of Information Technology in Construction, 16(2011), 477-492.

[2] Adriaanse, A., Voordijk, H., \& Dewul, G. (2010). The use of interorganisational ICT in United States construction projects. Automation in Construction, 19(1), 73-83.

[3] Ahuja, V., Yang, J., \& Shankar, R. (2009). Study of ICT Adoption for Building Project Management in the Indian Construction Industry. Automation in Construction, 18(4), 415-423.

[4] Alaghbandrad, A., Nobakht, M. B., Hosseinalipour, M., \& Asnaashari, E. (2011). ICT Adoption In The Iranian Construction Industry: Barriers And Opportunities. Paper presented at the The 28th International Symposium on Automation and Robotics in Construction, IAARC

[5] Aouad, G., Kagioglou, M., Hinks, R., \& Sexton, M. (1999). Technology Management of IT in Construction: A Driver or an Enabler? Journal of Logistics Information Management, 12(1/2), 130-137. 
[6] Beatty, R., Shim, J. P., \& Jones, M. C. (2001). Factors Influencing Corporate Web Site Adoption: A Time-Based Assessment. Information and Management, 38(6), 337354.

[7] Besner, C., \& Hobbs, B. (2004). An empirical investigation of project management practice: In reality what tools do practitioners use? In D. P. Slevin, D. I. Cleland, \& J. K. Pinto (Eds.), Innovations: Project Management Research (pp. 337-351). Newton Square: Project Management Institute.

[8] Brown, A. (2002). Organisational Culture. London: Pitman Publishing.

[9] Devaraj, S., \& Kohli, R. (2003). Performance Impacts of Information Technology: Is Actual Usage the missing link. Management Science, 49(3), 273-289.

[10] Doms, M., Dunne, T., \& Troske, K. (1997). Workers, wages and technology. The Quarterly Journal of Economics, 112(1), 253-290.

[11] Froese, T. M. (2010). The impact of emerging information technology on project management for construction. Automation in Construction, 19(5), 531-538. doi: http: //dx.doi.org/10.1016/j.autcon.2009.11.004

[12] Gichoya, D. (2012). Factors Affecting the Successful Implementation of ICT Projects in Government. The Electronic Journal of e-Government, 3(4), 175-184.

[13] Gilchrist, S., Gurbaxani, V., \& Town, R. (2001). PCs and the Productivity Revolution. Working Paper, Center for Research on Information Technology and Organizations. Retrieved from Irvine:

[14] Gordon, R. J. (2000). Does the "New Economy" Measure up to the Great Inventions of the Past. Journal of Economic Perspectives, 14(4), 49-74.

[15] Greenan, N., Mairesse, J., \& Topio-Bensaid, A. (2001). Information Technology, Productivity and Economic Growth: International Evidence and Implications for Economic Development. Cambridge: Oxford University Press.

[16] Gretton, P., Gali, J., \& Parham, D. (2004). The effects of ICTs and Complementary Innovations on Australian Productivity Growth. In OECD (Ed.), The Economic Impact of ICT. Measurement, Evidence and Implication (pp. 105-130). Paris.

[17] Hartmann, T., van Meerveld, H., Vossebeld, N., \& Adriaanse, A. (2012). Aligning building information model tools and construction management methods. Automation in Construction, 22(2012), 605-613. doi:http://dx.doi.org/10.1016/j.autcon.2011.12.011

[18] Hebert, J. E., \& Deckro, R. F. (2011). Combining contemporary and traditional project management tools to resolve a project scheduling problem. Computers \& Operations Research, 38(1), 21-32. doi: http://dx.doi.org/10.1016/j.cor.2009.12.004 
[19] Hollenstein, H. (2004). Determinants of the adoption of Information and Communication Technologies (ICT), An empirical analysis based on firm-level data for the Swiss business sector. Structural Change and Economic Dynamics, 15(3), 315-342.

[20] Hwang, B.-G., Zhao, X., \& Toh, L. P. (2014). Risk management in small construction projects in Singapore: Status, barriers and impact. International Journal of Project Management, 32(1), 116-124. doi: http://dx.doi.org/10.1016/j.ijproman.2013.01.007

[21] Ibrahim, A. R., Roy, M. H., Ahmed, Z., \& Imtiaz, G. (2010). An investigation of the status of the Malaysian Construction Industry. Benchmarking: An International Journal, 17(2), 294-308.

[22] Ika, L. A., Diallo, A., \& Thuillier, D. (2010). Project management in the international development industry. International Journal of Managing Projects in Business, 3(1), 61-93.

[23] Isikdag, U., J.Underwood, J., Kuruoglu, M., Goulding, J., \& Acikalin, U. (2009). Construction informatics in Turkey: strategic role of ICT and future research directions. Journal of Information Technology in Construction (ITcon), 14(2009), 412428.

[24] Jonsdottir, S., Ingason, H. T., \& Jonasson, H. I. (2014). Continuous Improvement Projects in Certified Organizations in Iceland: Traditional Projects or not? Procedia - Social and Behavioral Sciences, 119(2014), 142-151. doi: http://dx.doi.org/10.1016/j. sbspro.2014.03.018

[25] Jugdev, K., Perkins, D., Fortune, J., White, D., \& Walker, D. (2013). An exploratory study of project success with tools, software and methods. International Journal of Managing Projects in Business, 6(3), 534-551.

[26] Kometa, S., Olomolaiye, P., \& Harris, F. (1994). Attributes of UK construction clients influencing project consultants' performance. Construction Manage Econ, 12, 433443.

[27] Lee, S., Yu, J., \& Jeong, D. (2013). BIM Acceptance Model in Construction Organizations. Journal of Management in Engineering. doi:doi:10.1061/(ASCE)ME.19435479.0000252

[28] Lehr, B., \& Lichtenberg, F. (1999). Information Technology and its Impact on Productivity: Firm-level evidence from government and private data sources. The Canadian Journal of Economics, 32(2), 335-362.

[29] Mahmood, M. A., Hall, L., \& Swanberg, D. L. (2001). Factors Affecting Information Technology Usage: A Meta-Analysis Of The Empirical Literature. Journal of Organizational Computing and Electronic Commerce, 11(2), 107-130. 
[30] Milis, K., \& Mercken, R. (2002). Success factors regarding the implementation of ICT investment projects. Int. J. Production Economics, 80(1), 105-117.

[31] Mir, F. A., \& Pinnington, A. H. (2014). Exploring the value of project management: Linking Project Management Performance and Project Success. International Journal of Project Management, 32(2), 202-217. doi: http://dx.doi.org/10.1016/j. ijproman.2013.05.012

[32] Morgan, A., Colebourne, D., \& Thomas, B. (2006). The Development Of ICT Advisors For SME Businesses: An Innovative Approach. Technovation, 26(8), 980-987.

[33] Moriones, A. B., \& Lopez, F. L. (2007). A firm-level analysis of determinants of ICT adoption in Spain. Technovation, 27(6), 352-366.

[34] Murphy, A., \& Ledwith, A. (2007). Project Management Tools and Techniques in High-Technology SMEs. Management Research News, 30(2), 153-166.

[35] Mutesi, E. T., \& Kyakula, M. (2011). Application of ICT in the Construction Industry in Kampala. Second International Conference on Advances in Engineering and Technology, 263-269.

[36] Ollo-Lopez, A., \& Aramendia-Muneta, M. E. (2011). ICT impact competitiveness, innovation and environment. Telematics and Informatics, 29(2), 204-210.

[37] Pamulu, M. S., \& Bhuta, C. (2004). Managing Information Technology in Construction Industry: the Indonesian Experience. Paper presented at the CIB World Building Congress 2004..

[38] Papadaki, M., Gale, A. W., Rimmer, J. R., Kirkham, R. J., Taylor, A., \& Brown, M. (2014). Essential Factors that Increase the Effectiveness of Project/Programme Risk Management. Procedia - Social and Behavioral Sciences, 119(2014), 921-930. doi: http://dx.doi.org/10.1016/j.sbspro.2014.03.103

[39] Peansupap, V., \& Walker, D. H. T. (2005). Factors Enabling Information And Communication Technology Diffusion And Actual Implementation In Construction Organisations. Itcon, 10(2005), 193-218.

[40] Pereira, L., Tenera, A., \& Wemans, J. (2013). Insights on Individual's Risk Perception for Risk Assessment in Web-based Risk Management Tools. Procedia Technology, 9(2013), 886-892. doi: http://dx.doi.org/10.1016/j.protcy.2013.12.098

[41] Peterson, F., Hartmann, T., Fruchter, R., \& Fischer, M. (2011). Teaching construction project management with BIM support: Experience and lessons learned. Automation in Construction, 20(2), 115-125. doi: http://dx.doi.org/10.1016/j.autcon.2010.09.009

[42] PMI. (2013). A Guide to the Project Management Body of Knowledge (5th Edition). Newton Square, PA.: Project Management Institute. 
[43] Rogers, E. M. (2003). Diffusion of Innovations. New York: Free Press.

[44] Salas-Morera, L., Arauzo-Azofra, A., García-Hernández, L., Palomo-Romero, J. M., \& Hervás-Martínez, C. (2013). PpcProject: An educational tool for software project management. Computers \& Education, 69(2013), 181-188. doi: http://dx.doi.org/10. 1016/j.compedu.2013.07.018

[45] Sambasivan, M., \& Soon, Y. W. (2007). Causes and effects of delays in Malaysian construction industry. International Journal of Project Management, 25(5), 517-526. doi: http://dx.doi.org/10.1016/j.ijproman.2006.11.007

[46] Sanjuan, A. G., \& Froese, T. (2013). The Application of Project Management Standards and Success Factors to the Development of a Project Management Assessment Tool. Procedia - Social and Behavioral Sciences, 74(2013), 91-100. doi: http://dx.doi.org/ 10.1016/j.sbspro.2013.03.035

[47] Shtub, A. (1997). Project segmentation-a tool for project management. International Journal of Project Management, 15(1), 15-19. doi: http://dx.doi.org/10.1016/S02637863(96)00017-8

[48] Spalek, S. (2014). Does investment in project management pay off? Industrial Management \& Data Systems, 114(5), 832-856.

[49] Ssewanyana, J., \& Busler, M. (2007). Adoption and Usage of ICT in Developing Countries: Case of Ugandan Firms. International Journal of Education and Development using Information and Communication Technology (IJEDICT), 3(3), 4959.

[50] Stretton, A. (2007). A short history of modern project management. PMI World Today, 9(10), 1-18.

[51] Sukhoo, A., Barnard, A., Eloff, M. M., \& Van der Poll, J. A. (2004). A Survey Of Project Management Tools, Techniques And Methodologies Used In Mauritius: The Current Status. Paper presented at the Global Knowledge for Project Management Professionals.

[52] Taylor, S., \& Todd, P. A. (1995). Understanding Information Technology Usage: A Test of Competing Models. Information Systems Research, 6(2), 144-176.

[53] Todd, P., \& Benbasat, I. (1999). Evaluating the impact of DSS, cognitive effort, and incentives on strategy selection. Information Systems Research, 10(4), 356-374.

[54] Turner, J. R. (2008). The Handbook of Project-Based Management. New York: McGraw-Hill.

[55] Venkatesh, V., \& Morris, M. (2000). Why don't men ever stop to ask for directions? Gender, social influence, and their role in technology acceptance and usage behavior. MIS Quarterly, 24(1), 115-139. 
[56] Ventakesh, V., \& Bala, H. (2008). Technology Acceptance Model 3 and a Research Agenda on Interventions. Decision Sciences, 39(2), 273-315.

[57] White, D., \& Fortune, J. (2002). Current practice in project management-an empirical study. International Journal of Project Management, 20(1), 1-11. 